Para más información acerca del uso de las listas de distribución consultar la siguiente dirección: http//www.rediris.es/list/

A continuación se citan las listas de distribución que por su temática están directamente relacionados con el patrimonio arquitectónico.

- Preservatión-L

Tema: conservación y preservación de patrimonio arquitectural.

Idioma: inglés.

Suscripción: enviar el mensaje 'subscribe preservation-l" a listserv@netcom.com

- Conservation-research

Tema: conservación de objetos de arte y de edificios.

Idioma: inglés.

Más información:

http://www.mailbase.ac.uk/lists/conservation-research

- Conservation Distlist

Tema: conservación de materiales culturales. Idioma: inglés.

Suscripción: enviar el mensaje "subscribe

Distlist su nombre" a

consdist-request@lindy.stanford.edu

\section{- ICCOM-CC}

Tema: es una lista de distribución mantenida por "International Conservation Committee Council of Museums" (ICOM). Esta lista está abierta al público en general, pero sólo pueden mandar mensajes los miembros de la institución.

Idioma: inglés.

Suscripción: enviar el mensaje "subscribe ICCOM-CC nombre y apellido" a listserv@home.ease.lsoft.com

\section{- Engineering-masonry}

Tema: mampostería y su uso en ingeniería y construcción.

Idioma: inglés

Más información:

http://mailbase.ac.uk/lists/engineeringmasonry

- WAM-L

Tema: arquitectura en general.

Idioma: español e inglés.

Suscripción: enviar el mensaje "subscribe wam_l" a wam_I_mgr@izones.com.

- Arquitectura-I

Tema: arquitectura en general. Idioma: español.
Suscripción: enviar el mensaje "suscribe arquitectura-I nombre y apellido" a listserv@conicit.ve

Teresa Abejón Peña, Elena Fernández Sánchez Ángeles Maldonado Martínez

Centro de Información y Documentación Científica (CINDOC) (CSIC)

\section{Bibliografía}

Fernández Sánchez, Elena [et al.]. Urbanismo, Arquitectura y Construcción en Internet. Madrid: CINDOC, 1998. 201 p.

Fontes Blanco-Loizelier, Fernando L. Guía española de recursos en Internet sobre Prehistoria, Arqueología, Historia Antigua y Gestión del Patrimonio. Complutum, $n^{\circ}$ 8, 1997, pp. 374-385.

Ortega Vaquero, Isabel. "Webs de arquitectura: una aproximación y valoración de los recursos de información electrónicos nacionales". PH. Boletín del IAPH, n²2, 1998, pp. 123134

\title{
Paseos virtuales por Jaén: el patrimonio cultural de Úbeda y Baeza en Internet
}

El acceso multimedia a nuestra rica herencia cultural resulta cada vez más asequible y ofrece la posibilidad de conocer e incluso realizar una visita virtual a los monumentos y otros bienes históricos y naturales de las distintas provincias andaluzas.

En este caso, se ofrece una muestra de los distintos itinerarios culturales a través de Internet que se pueden realizar por Jaén, fundamentalmente por Úbeda y Baeza, unas de sus poblaciones con mayor riqueza patrimonial. Los destacados valores urbanísticos y arquitectónicos de estas ciudades, heredados de su época de esplendor en el siglo XVI, las convierte en candidatas a integrar la Lista de Sitios Patrimonio de la Humanidad de la UNESCO.
Iniciamos el recorrido con la página Web de Altavista "La base de datos de Andalucía" (http://www.bd-andalucia.es/), que a través del mapa de esta región ofrece acceso a diversos aspectos generales de las ocho provincias andaluzas, como el clima o el número de habitantes, y a una lista de municipios sobre los que se puede encontrar información más detallada relacionada con su historia, su cultura y sus monumentos, el ocio, las fiestas así como el transporte y otros servicios.

Concretamente destacamos el ejemplo de Úbeda. Después de consultar la breve reseña histórica a la que se accede a través del botón "Historia", se recomienda picar en el icono "Cultura", que nos conducirá a un paseo virtual por los monumentos más destacados de la ciudad, con breves descripciones de cada uno de ellos y fotografías de los más destacados.

El siguiente itinerario que destacamos por su calidad, aunque los textos están redactados en inglés, ha sido diseñado por la Universidad de Granada (http://kal-el.ugr/ubeda.html). El sitio web se inicia con una descripción concisa de los principales monumentos de Úbeda y Baeza y de la singularidad del desarrollo artístico del Renacimiento en las dos localidades.

A continuación, puede realizarse un ameno recorrido por el patrimonio arquitectónico de esta ciudad, acompañado de bellas imágenes y de reseñas, en algunos casos bastante exhaus- 


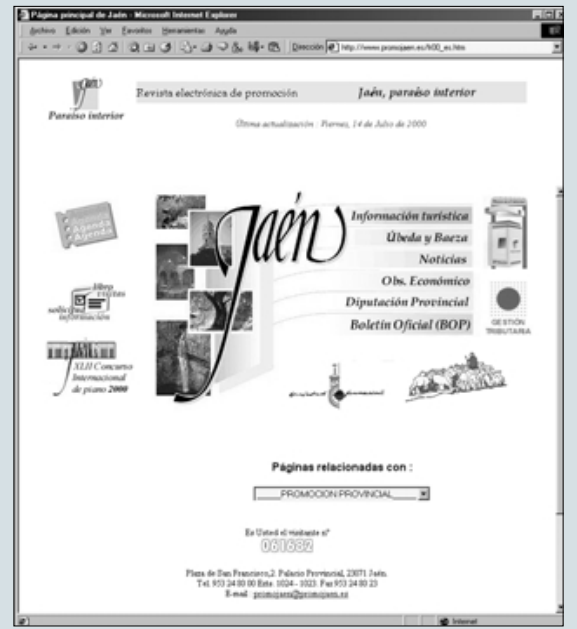

tivas y cuidadas, de los monumentos de Úbeda, sus autores, elementos arquitectónicos, etc., siempre situándolos en su espacio geográfico y relacionándolos con su entorno.

Por otro lado, la página http://www.spa.es/turismo/spain/jae.htm/, realizada en colaboración con los ayuntamientos correspondientes, ofrece guías turísticas de las ciudades de Jaén, Úbeda y Baeza en las que, además de toda aquella información y datos prácticos que en general interesan al viajero, se facilita el acceso a una breve pero completa información de algunos de los monumentos de las tres ciudades. Junto a cada texto aparece un icono que se debe pulsar para obtener la fotografía de la obra en cuestión.
La Universidad de Jaén, por su parte, dispone de una página (http://www.ujaen.es/jaen/index.html) con una guía en la que puede encontrarse información turística y cultural de toda la provincia. A través de ésta es posible acceder a sitios Web de itinerarios culturales, rutas de arte y artesanía o información de museos, entre otros, desarrollados por diversas instituciones.

De ellos destaca "Jaén en 48 horas", también de la Universidad de Jaén, que a través de un índice inicial propone diversas rutas artísticas, religiosas, ecológicas, gastronómicas, etc. En concreto, hemos escogido la "Ruta del Renacimiento" (http://www.ujaen.es/jaen/jaen48h/guia04.html, que se centra en Baeza y Úbeda, ciudades con destacados ejemplos de la arquitectura renacentista en Andalucía.

Estos itinerarios virtuales por las dos ciudades jiennenses ofrecen un amplísimo volumen de información de su patrimonio monumental y una minuciosa descripción del recorrido, con el único inconveniente de la ausencia de imágenes fotográficas y de un diseño abigarrado que no se adecúa al estilo habitual de la información en Internet.

Por último, el Patronato de Promoción Provincial y Turismo de Jaén (http://www.promojaen.es/) dispone de una moderna y atractiva página en Internet y propone opciones interesantes.
Por un lado, a través del botón "Baeza y Úbeda, Patrimonio de la Humanidad" encontramos un apartado creado para apoyar y justificar la candidatura de estas ciudades a integrarse en la Lista del Patrimonio de la Humanidad de la UNESCO. Además de destacar sus valores patrimoniales excepcionales, en esta sección se especifica la superficie de los conjuntos monumentales propuestos para su inclusión, las zonas que abarcan, etc., así como los objetivos que se persiguen con la solicitud de ser declaradas como Patrimonio de la Humanidad.

Por otro lado, utilizando el botón de "Turismo cultural" nos encontramos con una más amplia gama de posibilidades y con un diseño mucho más atractivo y actualizado, que permite navegar de forma ágil y sencilla por las distintas secciones de la página Web. Así, sirvan como ejemplo los botones dedicados a las "Ciudades monumentales", donde volvemos a encontrar Úbeda y Baeza, a los "Monumentos BIC" o a las "Rutas culturales".

En todos los casos aparecen los textos descriptivos de los lugares y obras a los que se hace referencia, acompañados de diversas fotografías. Además, se ofrece la posibilidad de acceder a los planos de los centros históricos y a imágenes de vídeo de las zonas descritas.

María Victoria Madrid Díaz Centro de Documentación del IAPH

\section{Direcciones web de interés sobre Itinerarios y Rutas Culturales por Andalucía y España}

\section{ITINERARIOS CULTURALES POR ANDALUCÍA}

\section{Bienvenido a TurAndalucía} http://www.turandalucia.com

Sitio con una alta calidad gráfica y visual, que informa al visitante sobre posibles rutas a seguir según el tema elegido. Asimismo, da información geográfica sobre las provincias, sitios con encanto, legados históricos, pueblos, etc.

\section{Itinerario de Almorávides y \\ Almohades entre Andalucía y \\ Marruecos \\ (Legado Andalusí) \\ http://www.legadoandalusi.es/ \\ itinerarios.htm}

Itinerario entre Andalucía y Marruecos. Se accede a través de un mapa sensible dividido según las zonas en 7 itinerarios distintos donde se destacan aspectos históricos y artísticos de la zona, entre otros.

\section{La Sevilla Histórica}

http://www.disbumad.es/sevilla/historia/

Recorrido por Sevilla Capital, siguiendo sus etapas históricas.

\section{Las Rutas del Legado Andalusí}

http://www.legadoandalusi.es/rutas/rutas.htm Se nos presentan una serie de rutas históricas de la época ,entre Granada y Algeciras, Córdoba, Lisboa, Murcia, Navas de Tolosa,Sevilla o Tánger. 